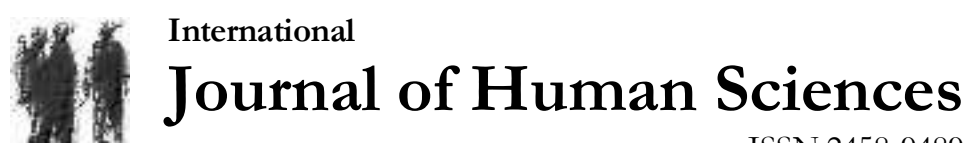 \\ ISSN:2458-9489
}

Volume 15 Issue 1 Year: 2018

\section{Utilization of active and passive constructions in English academic writing}

\author{
Erdoğan Bada ${ }^{1}$ \\ Ömer Gökhan Ulum²
}

\begin{abstract}
By its nature, AW represents adversity compared to other types of writing. It owns the characteristics of more notable patterns and language usage compared to other writing styles such as literary works, news, etc. Without discriminating the language used, this kind of writing generally bears similarities across languages due to the description and representation of scientific concepts. Therefore, there stands a must that objectivity is observed in AW as much as possible. In terms of language usage, diverse structures may be seen to be used in varied frequencies. Within this study, articles written in English and published in scientific journals covered by high ranking field indices such as Social Sciences Citation Index, Science Citation Index/Health Sciences Library, and American-Eurasian Network for Scientific Information were perused depending on their related fields classified as the Social Sciences, Natural and Applied Sciences, and Health Sciences, and then active/passive dispersion of these articles was identified through descriptive content analysis. The results suggest that active structure usage $(61 \%)$ in overall analysis outnumbered that of passive $(39 \%)$; the decline in its utilization depending on fields is rather significant, in that while the gap between active (74\%) and passive (26\%) usage in Social Sciences is rather wide in favor of active construction, we can observe a significant narrowing of the divide in Natural and Applied Sciences (60\% active, $40 \%$ passive), and Health Sciences (51\% active, $49 \%$ passive). The findings of this descriptive study may contribute to prospective research carried out in the specified fields in AW.
\end{abstract}

Keywords: Academic Writing; English Academic Writing; Active Voice; Passive Voice

\section{Introduction}

However hard and/or complex it may be, the journey to being an academic writer is a significant practice. It is a path which directs writers to new findings about themselves, their perspectives, their environment, and their identities as researchers ("Defining and understanding," 2017). AW is a type of judgement requiring writers to display intelligence and competency with specific skills of thinking, defining, and performing (Irvin, 2010). It is one of the main compounds of the academic world since it is a way to show insight about a peculiar topic or term - possibly the most demanding side of academia as the writer has to express himself or herself rigorously. Having a formal structure, AW requires scholars to write in full grammatical sentences, expressing

\footnotetext{
1 Prof. Dr., Çukurova University, Education Faculty, ELT Department, erdoganbada@gmail.com

2 Lecturer, Adana Science and Technology University, School of Foreign Languages, omergokhanulum@gmail.com Submitted:2018-02-28 Published: 2018-03-15 We would like to thank the Çukurova University Research Fund for their financial support throughout the study (project number: SBA2017-8125)
} 
Bada, E., \& Ulum, Ö. G. (2018). Utilization of active and passive constructions in English academic writing. Journal of Human Sciences, 15(1), 413-421. doi:10.14687/ihs.v15i1.5256

knowledge in a coherent and brief way, and being based on research, instead of personal views. AW is efficient in tone and stands objective by refraining from mentioning people or feelings straight, but highlights objects, evidence and notions ("Academic Writing," 2017a). Writing necessitates diverse orientations like being guided by the voices of others, as well as your own voice ("Defining and understanding," 2017). Using a formal language and references from academic field to bolster the points being made, AW is not an irregular way of communication, and diverges remarkably from everyday writing ("Academic writing," 2017b). That's to say, having specific rules; AW is enormously different from personal writing, in that it is based on a formal structure ensuring that opinions are reinforced by citations from the related literature, besides concerning the underlying theories. It adopts a peculiar 'tone' and maintains classical grammar practices ("What is academic writing?," 2017; "Organizing your social," 2017); is based on exquisite grammar and accurate word structure through which the writer competently expresses himself or herself properly. The writing procedure covers the precise meaning distinctions of the verb- tense system, the use of modal verbs to assert extent of certainty, and different ways of categorising and arranging written information to highlight the stream of argument (Lynch and Anderson, 2013). In AW, we generally do not desire to emphasize who acts, rather we hint on who receives or experiences the action instead. Therefore, the passive voice is highly favourable in AW as it gives writers the opportunity to stress the most important participants in sentences by putting them at the beginning of a sentence (Hyland, 2002; "Why use the passive," 2017). On the other hand, while commonly seen as referring to a complete impersonal tone in AW-through removing or understating the subject of a sentence, passive voice can also be employed to disclose the attitude of the writer. In spite of being associated with objectivity, which may also indicate the contrary, the passive voice might also be used with this regard in which writers disclose their perspectives, beliefs, and evaluations (Baratta, 2009; Sigel, 2009). In the $20^{\text {th }}$ century, the passive voice was a fundamental element in scientific writing; yet, there has been a conspicuous change in this regard. For instance, a leading publication manual, APA [6th edition]), encourages the active voice for accuracy and briefness. For scholars, the common view is that the passive voice constructs clear writing and suggests avoidance of responsibility ("Active and passive," 2017). However, using the active voice for most sentences makes the meaning clearer for readers, and results in uncomplicated sentences. Using too much passive voice may, on the other hand, impair the meaning of sentences even in scientific writing ("Active versus passive," 2017). In other words, the use of the passive may result in texts in which sources or agents are not apparent, and accordingly the readers are likely to lose sight of any agent. Thus, the writer should not hesitate to employ the active voice - particularly in the Discussion part of a research paper, where it is sometimes crucial to state one's own beliefs and views regarding a specific issue. In the Methods part of several research studies as in Medicine, for instance, it is tolerable to break the continuity of several passive voice sentences by some active voice sentences ("Active or passive voice," 2017).

In a study conducted by Jisa, Reilly, Verhoeven, Baruch, and Rosado (2002), the dispersion of passive forms was investigated in written texts developed by natives of English, French, Dutch, Spanish, and Hebrew languages which differ in the range of passive formation to upgrade a patient and to lower an actor in encoding an event. The findings of this study revealed notable influences of language and age in that across the mentioned languages, passive usage significantly increased with age. Different from the study of Jisa, Reilly, Verhoeven, Baruch, and Rosado (2002), this research investigates the frequency of active and passive voice utilisation in Social Sciences, Natural and Applied Sciences, and Health Sciences. Therefore, with this in mind, we sought responses to the following research questions:

1. What is the dispersion of active/passive voice constructions in parts (abstract, introduction, methodology, discussion and conclusion) of scientific articles across Social Sciences, Natural and Applied Sciences, and Health Sciences? 
Bada, E., \& Ulum, Ö. G. (2018). Utilization of active and passive constructions in English academic writing. Journal of Human Sciences, 15(1), 413-421. doi:10.14687/jhs.v15i1.5256

2. To what extent do scientific articles in journals of Social Sciences employ active/passive voice constructions?

3. To what extent do scientific articles in journals of Natural and Applied Sciences employ active/passive voice constructions?

4. To what extent do scientific articles in journals of Health Sciences employ active/passive voice constructions?

\section{Data Collection}

The data for this study was collected from 60 articles from the science fields of Social Sciences, Natural and Applied Sciences, and Health Sciences: 20 from each. The articles were selected from a list of journals covered by the Social Sciences Citation Index, Science Citation Index/Health Sciences Library, and American-Eurasian Network for Scientific Information indices. The rationale underlying the selection of the articles in question is that the publishing journals were covered by high ranking indices of the related fields. The most recent articles were randomly selected.

Each article was examined with a focus on the frequency of active and passive sentence constructions. All parts in related articles were perused, and, as a result employed active and passive structures were identified.

\section{Findings and Results}

As a first step, for the extent of active and passive structures, frequency information was obtained utilizing the SPSS statistical package. At a second stage, a chi-square test was run in order to identify any significant difference in the dispersion of overall themes for each item. Following this, examples for each category were given in sentences regarding active/passive sentence structures. These steps were followed for each field of science in question.

\subsection{Active/Passive Structures of the Parts of Articles Covered by the Social Sciences, Natural and Applied Sciences, and Health Sciences}

This group consists of five parts as abstract, introduction, methodology, discussion and conclusion with each emerging frequency and related percentages of active and passive structures. In Table 1, we can observe the frequencies of active and passive structures employed in the parts of the articles from Social Sciences.

Table 1

Active and Passive Rates of Social Sciences

\begin{tabular}{lccccc}
\hline Parts & \multicolumn{5}{c}{ Social Sciences } \\
\hline & \multicolumn{2}{c}{ Active } & \multicolumn{1}{c}{ Passive } & Chi-Square \\
\hline Abstract & $\mathbf{f}$ & $\mathbf{0}$ & $\mathbf{f}$ & $\mathbf{\%}$ & $\mathbf{p}$ \\
Introduction & 187 & 75 & 63 & 25 & 0.000 \\
Methodology & 815 & 72 & 235 & 28 & 0.000 \\
Discussion and & 1519 & 79 & 413 & 34 & 0.000 \\
Conclusion & & & & & 0.000 \\
\hline
\end{tabular}

As can be observed from Table 1, we can clearly see that the active structures in the abstracts of Social Sciences (75\%) were observed to highly outnumber the passive structures $(25 \%)$. As for the introduction, active usage was observed to be $72 \%$, while passive utilisation remained at $28 \%$. Regarding the methodology part, it can easily be seen from the table that active structure usage was recorded as $66 \%$ significantly outnumbering passive utilisation (34\%). The discussion 
Bada, E., \& Ulum, Ö. G. (2018). Utilization of active and passive constructions in English academic writing. Journal of Human Sciences, 15(1), 413-421. doi:10.14687/jhs.v15i1.5256

and conclusion part, similarly, presents a correlating picture of active and passive usage $(79 \% ; 21 \%)$ as was the case with other parts

As for Natural and Applied Sciences, Table 2 illustrates active and passive usage in journals covered in this field.

Table 2

Active and Passive Rates of Natural and Applied Sciences

\begin{tabular}{lccccc}
\hline Parts & \multicolumn{5}{c}{ Natural and Applied Sciences } \\
\hline & Active & \multicolumn{2}{c}{ Passive } & Chi-Square \\
\hline Abstract & $\mathbf{f}$ & $\mathbf{0}$ & $\mathbf{f}$ & $\mathbf{\%}$ & $\mathbf{p}$ \\
Introduction & 122 & 45 & 148 & 55 & 0.114 \\
Methodology & 1023 & 66 & 555 & 34 & 0.000 \\
Discussion and & 306 & 56 & 245 & 44 & 0.000 \\
Conclusion & & & & & \\
\hline
\end{tabular}

From Table 2, we can observe that active structures in the abstracts of Natural and Applied Sciences were fewer $(45 \%)$ than passive structures $(55 \%)$. As for the introduction part, active usage was observed to be employed by $66 \%$, significantly surpassing passive utilisation (34\%). Regarding the methodology part, it can be seen from the table that active structure usage occurred by $57 \%$, while the passive forms remained at $43 \%$. In parallel to introduction and methodology, the discussion and conclusion part embodied significantly more active structures (56\%) than passive ones $(44 \%)$.

Active/passive utilisation in the analysed journals of Health Sciences is illustrated in Table 3. According to our analyses, we can state that the dispersion of these structures in this particular field is significantly different from that of the previously discussed fields.

Table 3

Active and Passive Rates of Health Sciences

\begin{tabular}{lccccc}
\hline Parts & \multicolumn{5}{c}{ Health Sciences } \\
\hline & Active & \multicolumn{2}{c}{ Passive } & Chi-Square \\
\hline Abstract & $\mathbf{f}$ & $\mathbf{\%}$ & $\mathbf{f}$ & $\mathbf{0}$ & $\mathbf{p}$ \\
Introduction & 692 & 56 & 119 & 44 & 0.045 \\
Methodology & 631 & 64 & 382 & 36 & 0.000 \\
Discussion and & 1412 & 51 & 1406 & 49 & 0.911 \\
Conclusion & & & & & \\
\hline
\end{tabular}

As can be observed from Table 3, we can clearly see that active structures in the abstracts of Health Sciences include more active structures (56\%) than passive forms (44\%). As for the introduction part, active utilisation in this field was recorded as $64 \%$, while passive structures remained at 36\%. The methodology, and discussion and conclusion parts display a rather different picture; in that the difference in the utilisation of active and passive structures does not seem to be statistically significant (for methodology: 43\% active, 57\% passive; for discussion and conclusion: $51 \%$ active, $49 \%$ passive).

A chi-square test conducted for Social Sciences articles yields statistically significant results in favour of active structure $(p=0.000)$. As for Natural and Applied Sciences, the conducted chisquare test, apart from the abstract part $(\mathrm{p}=0.114)$, yields statistically significant results in favour of 
Bada, E., \& Ulum, Ö. G. (2018). Utilization of active and passive constructions in English academic writing. Journal of Human Sciences, 15(1), 413-421. doi:10.14687/jhs.v15i1.5256

active usage $(\mathrm{p}=0.000)$. Although, in the abstract, the utilisation of active and passive constructions does not seem to display much variation, the slight difference is in favour of passive construction usage. Our analysis of articles in Health Sciences reveals a picture different from that of Social and Natural Applied Sciences, in that while the introduction part embodies statistically more active structures $(\mathrm{p}=0.000)$, the methodology, and discussion and conclusion parts do not seem to present a statistically significant utilisation of either construction $(\mathrm{p}=0.910 ; \mathrm{p}=0.911$ respectively). As for the abstract in this area, the slight difference $(\mathrm{p}=0.045)$ works in favour of active constructions.

\subsection{Overall Active/Passive Structures in Journals of Diverse Fields}

This group of journals consists of two categories as active and passive structures with each emerging frequency and related percentages. In Table 4, we can observe the frequencies and related percentages of active and passive structures employed in journals of Social Sciences, Natural and Applied Sciences, and Health Sciences.

Table 4

Active and Passive Structures of Overall Fields of Sciences

\begin{tabular}{lccccc}
\hline Fields & \multicolumn{2}{c}{ Active } & \multicolumn{2}{c}{ Passive } & Chi-Square \\
\hline Social Sciences & f & $\mathbf{0}$ & f & $\mathbf{\%}$ & p \\
Natural and Applied Sciences & 3126 & 74 & 1112 & 26 & 0.000 \\
Health Sciences & 2542 & 60 & 1708 & 40 & 0.000 \\
Total & 2888 & 51 & 2728 & 49 & 0.033 \\
\hline
\end{tabular}

From Table 4, we can clearly understand that active structures for Social Sciences $(74 \%)$ were observed to significantly outnumber their passive counterparts $(26 \%)$. In line with this result, we can see that journals in Natural and Applied Sciences embodied active constructions by $60 \%$ as opposed to a $40 \%$ utilisation of the passive structure. As we move to Health Sciences, despite the fact that the difference between active and passive usage is not statistically significant, the percentages however (active: $51 \%$; passive: $49 \%$ ) are so close that we can surmise that the tendency in this field is towards employment of both structures almost equally. An overall analysis reveals that the active sentence structure, by $61 \%$, was seen to emerge with statistically significant dominance compared to its passive counterpart, which remained at 39\%. The non-parametric chisquare test for all fields reveals statistically significant differences between the two structures in favour of the active sentence construction (Social Sciences: $p=0.000$; Natural and Applied Sciences: $p=0.000$; Health Sciences: $p=0.033$ ). To cite some sample sentences from the articles, we present the following excerpts:

\section{Social Sciences}

\section{Active}

To start with, eye fixations enable humans to perceive visual information using highly accurate foveal vision (Rayner, 2009, as cited in Seywerth, Valuch, and Ansorge, 2017).

One explanation for the lack of evidence for cognitive top-down influences on early fixation selection after cuts is the choice of stimuli and viewing tasks of previous studies (Dorr, Martinetz, Gegenfurtner, and Barth, 2010; Goldstein, Woods, and Peli, 2007, as cited in Seywerth, Valuch, and Ansorge, 2017).

\section{Passive}

Metacognition is often referred to as the process of thinking about one's thinking. (Gutierrez de Blume, Wells, Davis, and Parker, 2017).

These studies, while useful to our understanding of calibration, are limited due to their dependence on normative, aggregated statistical data and .... (Gutierrez de Blume, Wells, Davis, and Parker, 2017). 
This article explores three Korean high school teachers' experiences of carrying out practitioner inquiry, a concept that includes multiple genres of research such as action research, teacher research, and self-study... (Ro, 2017).

We use the qualitative instrumental case study to study critical patriotism in teachers (Chua and $\operatorname{Sim}, 2017)$.

One must identify such skills, define them, organize different 21 st century skills into coherent systems, develop, and adapt curricula to include such skills ... (Geisinger, 2016).

\section{Natural and Applied Sciences}

\section{Active}

It is critical to fertility maintenance and enhancement of productivity (Nwite, 2017).

The casting and solidification quality is utmost important for fatigue component design (Chidambaram, 2017).

Magnesium Aluminium alloys have received significant interest due to casting characteristics and their high machining (Nagaraj and Gopalakrishnan, 2017).

Fig 4 shows the SEM morphology of alumina erodent which has angular morphology (Sathiyamoorthy, Shanmugam, and Balasubramanian, 2017).

Web Searching and navigating have become part of our daily online lives (Manjula and Chilambuchelvan, 2017).
The data for this study were collected in two ways: interviews and artefacts (Ro, 2017).

In Singapore, critical patriotism is enacted with a different spirit: one favoring consensus as opposed to confrontation, one favoring gradual change over radical change (Chua and Sim, 2017).

The present issue of Applied Measurement in Education is devoted to an important and timely topic... (Geisinger, 2016).

\section{Passive}

In the present study failed crank material ASTM A536 GR 80-55-06 has been analyzed and examined (Chidambaram, 2017).

Soil organic matter has been identified as a primary attribute of soil quality assessment for agricultural production (Batjes, 2011 as cited in Nwite, 2017).

Moulding has been done three composition magnesium with $0 \%$ of aluminium and $1 \%$ aluminium and $2 \%$ of aluminium by utilising electric resistance furnace (Nagaraj and Gopalakrishnan, 2017).

Titania or Titanium di-oxide (TiO2) and blend with $10 \% \mathrm{SiC}$ coatings were produced by High Velocity oxy Fuel (HVOF) spraying on commercially pure titanium substrate (Sathiyamoorthy, Shanmugam, and Balasubramanian, 2017).

The information is given to the end-user with the top most ranking data within the stipulated time and the remaining top information will be moved to the data repository for future use (Manjula and Chilambuchelvan, 2017). 
Bada, E., \& Ulum, Ö. G. (2018). Utilization of active and passive constructions in English academic writing. Journal of Human Sciences, 15(1), 413-421. doi:10.14687/ihs.v15i1.5256

\section{Health Sciences}

\section{Active}

While the qNMR approach is effective and makes it easier to determine the RRFs for impurities, it also has the advantage of allowing the universal detection of protons... (Liu, Yao, Zhang, and $\mathrm{Hu}, 2017$ ).

This study aimed to develop a mucoadhesive polymeric excipient comprising curcumin for buccal delivery (Laffleur, Schmelzle, Ganner, and Vanicek, 2017).

Development of palatable formulations for pediatric and geriatric patients involves various challenges (Chandrasekaran and Kandasamy, 2017).

Celecoxib (CXB) is a poorly aqueous solubility sulfonamide non-steroidal anti-inflammatory drug (NSAID) (Cao, Ren, and Chen, 2017).

An immediate release dose causes extrapyramidal side effects (Helal, Mortada, and Sallam, 2017).

\section{Discussion and Conclusion}

\section{Passive}

The relative response factors (RRFs) of ten cefazolin impurities were determined by quantitative nuclear magnetic resonance (qNMR) and high-performance... (Liu, Yao, Zhang, and $\mathrm{Hu}, 2017)$.

Hyaluronic acid (HA) as polymeric excipient was modified by immobilization of thiol bearing ligands (Laffleur, Schmelzle, Ganner, and Vanicek, 2017).

However, an innovative development with beneficial characteristics of marketed formulations in a single formulation platform was attempted (Chandrasekaran and Kandasamy, 2017).

Hence, the formulation of CXB was selected for solubilisation and bioavailability (Cao, Ren, and Chen, 2017).

In this work, a novel nanolipomer carrier system for PPD with enhanced intestinal permeability and sustained release properties has been developed and optimized. (Helal, Mortada, and Sallam, 2017).

Active/passive utilisation ratio in academic journals is an interesting point, and needs to be investigated in academic writing in order to shed light on the trend of which the writer may not be aware. Such investigations should probably aid academic writers in the choice of the most appropriate sentence structures. We believe that this study has proven to be one further step in this direction. The results obtained from this piece of research seem to validate the encouragement of APA [6th edition], which promotes the employment of active rather than passive constructions.

Inquiries into the employment of passive voice in different forms of writing, as in undergraduate essays, are general, and they include a shift in focus from performer to the influenced, therefore, admitting the author's attitude. Yet, intricate studies covering scientific writings are occasional, and this study serves the field with its relatively significant scope of coverage of different fields of sciences. Former reports on the requirement for a more direct style of writing were individual perspectives; yet, as was indicated by Leong (2014), the passive voice was once used extensively in scholarly papers, and apparently later writing styles such as APA, have reversed the trend (Hinkel, 2004).

Different from, and probably an extension to a study conducted by Jisa, Reilly, Verhoeven, Baruch, and Rosado (2002), where the dispersion of passive forms was investigated in written texts developed by natives of English, French, Dutch, Spanish, and Hebrew, our study, with disregard of age, focused on the utilization of active/passive constructions specific to science fields instead. From this perspective, it is probably the first of its kind yielding the following findings:

- In the fields of Social Sciences, Natural and Applied Sciences, and Health Sciences, the utilization of active structures is more prevalent than passive structures. 
Bada, E., \& Ulum, Ö. G. (2018). Utilization of active and passive constructions in English academic writing. Journal of Human Sciences, 15(1), 413-421. doi:10.14687/jhs.v15i1.5256

- The employment of active forms significantly surpasses the usage of passive structures in Social Sciences, compared to active/passive dispersion in Natural and Applied Sciences, as well as Health Sciences.

- Active structures in abstracts of Social Sciences and Health Sciences significantly surpass passive utilization, while the case is opposite in Natural and Applied Sciences where passive constructions were found to be more prevalent than active structures.

- The employment of active structures in the introduction parts of papers in all field sciences is significantly more prevalent than passive usage.

- Active usage in the methodology part of Social Sciences, and Natural and Applied Sciences significantly surpassed passive utilization, while the situation is opposite in Health Sciences, where passive constructions were used much more frequently than active ones.

- Although with varying frequencies, active utilization was found to be employed much more the passive structure in the discussion and conclusion parts of papers in all science fields.

Detailed studies focusing on structures employed in scientific writing are rare, let alone a narrower topic such as active/passive constructions. Therefore, this particular research, with its descriptive findings, may prove to be of some help for scholars interested in the field.

\section{Acknowledgment}

We would like to thank the Çukurova University Research Fund for their financial support throughout the study (project number: SBA-2017-8125).

\section{References}

American Psychological Association. (1983). Publication manual. American Psychological Association.

Academic Writing. (2017a, Augst 06). Retrieved from https://www.usq.edu.au/currentstudents/new-to-usq/before-you-start/get-ready-to-study/academic-writing

Academic Writing. (2017b, Augst 06). Retrieved from https://www.uts.edu.au/currentstudents/support/helps/self-help-resources/academic-writing

Active and Passive Voice in Academic Writing. (2017, Augst 06). Retrieved from https://www.enago.com/academy/active-and-passive-voice-in-academic-writing/

Academic writing: language and style. (2017, Augst 06). Retrieved from https://library.leeds.ac.uk/info/485/academic skills/331/academic writing/5

Active or passive voice? (2017, Augst 06). Retrieved from http://www.monash.edu.au/lls/llonline/writing/general/lit-reviews/5.xml

Active Versus Passive Voice. (2017, Augst 06). Retrieved from https://owl.english.purdue.edu/owl/resource/539/02/

Baratta, A. M. (2009). Revealing stance through passive voice. Journal of pragmatics, 41(7), 1406-1421.

Cao, M., Ren, L., \& Chen, G. (2017). Formulation Optimization and Ex Vivo and In Vivo Evaluation of Celecoxib Microemulsion-Based Gel for Transdermal Delivery. AAPS PharmSciTech, 18(6), 1960-1971.

Chandrasekaran, P., \& Kandasamy, R. (2017). Development of Oral Flexible Tablet (OFT) Formulation for Pediatric and Geriatric Patients: a Novel Age-Appropriate Formulation Platform. AAPS PharmSciTech, 18(6), 1972-1986.

Chidambaram, S. (2017). Failure investigation of an industrial crankshaft made of ductile iron. Carbon, 3, 3-90.

Chua, S., \& Sim, J. B. Y. (2017). Rethinking critical patriotism: a case of constructive patriotism in Social Studies teachers in Singapore. Asia Pacific Journal of Education, 37(1), 1-13.

Defining and understanding academic writing. (2017, Augst 06). Retrieved from https://www.mheducation.co.uk/openup/chapters/0335219330.pdf 
Bada, E., \& Ulum, Ö. G. (2018). Utilization of active and passive constructions in English academic writing. Journal of Human Sciences, 15(1), 413-421. doi:10.14687/ihs.v15i1.5256

Geisinger, K. F. (2016). 21st Century Skills: What Are They and How Do We Assess Them?. Applied Measurement in Education, 29(4), 245-249.

Gutierrez de Blume, A. P., Wells, P., Davis, C., \& Parker, J. (2017). "You Can Sort of Feel It": Exploring Metacognition and the Feeling of Knowing Among Undergraduate Students. The Qualitative Report, 22(7), 2017-2032. Retrieved from http://nsuworks.nova.edu/tqr/vol22/iss 7/18

Helal, H. M., Mortada, S. M., \& Sallam, M. A. (2017). Paliperidone-Loaded Nanolipomer System for Sustained Delivery and Enhanced Intestinal Permeation: Superiority to Polymeric and Solid Lipid Nanoparticles. AAPS PharmSciTech, 18(6), 1946-1959.

Hinkel, E. (2004). Tense, aspect and the passive voice in L1 and L2 academic texts. Language teaching research, 8(1), 5-29.

Hyland, K. (2002). Options of identity in academic writing. ELT journal, 56(4), 351-358. Irvin, L. L. (2010). What Is "Academic" Writing?. writingspaces, 1, 3.

Jisa, H., Reilly, J., Verhoeven, L., Baruch, E., \& Rosado, E. (2002). Passive voice constructions in written texts: A cross-linguistic developmental study. Written Language \& Literacy, 5(2), 163-181.

Laffleur, F., Schmelzle, F., Ganner, A., \& Vanicek, S. (2017). In vitro and ex vivo evaluation of novel curcumin-loaded excipient for buccal delivery. AAPS PharmSciTech, 18(6), 21022109.

Leong, P. A. (2014). The passive voice in scientific writing. The current norm in science journals.

Liu, S., Yao, S., Zhang, H., \& Hu, C. (2017). Determination of Relative Response Factors of Cefazolin Impurities by Quantitative NMR. AAPS PharmSciTech, 18(6), 1895-1900.

Lynch, T., \& Anderson, K. (2013). Grammar for academic writing. English Language Teaching Centre. University of Edinburgh.

Manjula, R. \& Chilambuchelvan, A. (2017). An Efficient Approach For Indexing Web Pages Using Various Similarity Features. Advances in Natural and Applied Sciences. 11(9), 126-133.

Nagaraj, A. \& Gopalakrishnan, S. (2017). Optimization of Tribological Properties of Magnesium2\% Aluminium Alloys Using Design Of Experiment. Advances in Natural and Applied Sciences. 11(8), 15-24.

Nwite, J., N. (2017). Importance Of Soil Organic Matter In Fertility Maintenance And Productivity Under Farming Management System In Abakaliki, Nigeria. Advances in Natural and Applied Sciences. 11(9), 1-9.

Organizing Your Social Sciences Research Paper: Academic Writing Style. (2017, Augst 06). Retrieved from http://libguides.usc.edu/writingguide/academicwriting

Ro, J. (2017). A journey from the classroom to the world of educational reform: a study of three Korean teachers' practitioner inquiry. Asia Pacific Journal of Education, 37(1), 28-41.

Sathiyamoorthy, R., Shanmugam, K. \& Balasubramanian, V. (2017). Erosive wear behaviour of SiC reinforced Titania coating deposited by High Velocity Oxy (HVOF) fuel spraying. Advances in Natural and Applied Sciences. 11(8), 9-14.

Seywerth, R., Valuch, C., \& Ansorge, U. (2017). Human Eye Movements After Viewpoint

Shifts in Edited Dynamic Scenes are Under Cognitive Control. Advances in cognitive psychology, 13(2), 128.

Sigel, T. (2009). How passive voice weakens your scholarly argument. Journal of Management Development, 28(5), 478-480.

What is an Academic Paper?. (2017, Augst 06). Retrieved from https://depts.washington.edu/owrc/Handouts/What $\% 20$ is $\% 20$ an $\% 20$ Academic $\% 20$ Pape r.pdf

What is academic writing?. (2017, Augst 06). Retrieved from http://owll.massey.ac.nz/academicwriting/what-is-academic-writing.php

WHY use the passive voice in academic writing?. (2017, Augst 06). Retrieved from https://unilearning.uow.edu.au/academic/3avi.html 